\title{
Perspectives on the diagnostic, predictive and prognostic markers of neuroendocrine neoplasms (Review)
}

\author{
OANA ALEXANDRA CIOBANU ${ }^{1,2}$, SORINA MARTIN ${ }^{1,2}$ and SIMONA FICA ${ }^{1,2}$ \\ ${ }^{1}$ Department of Endocrinology and Diabetes, Elias Hospital, 011461 Bucharest; ${ }^{2}$ Department of Endocrinology, \\ Carol Davila University of Medicine and Pharmacy, 20021 Bucharest, Romania
}

Received July 27, 2021; Accepted September 23, 2021

DOI: $10.3892 /$ etm.2021.10914

\begin{abstract}
Neuroendocrine neoplasms (NENs) are a heterogeneous group of rare tumors with different types of physiology and prognosis. Therefore, prognostic information, including morphological differentiation, grade, tumor stage and primary location, are invaluable and contribute to the formulation of treatment decisions. Biomarkers that are currently used, including chromogranin A $(\mathrm{CgA})$, serotonin and neuron-specific enolase, are singular parameters that cannot be used to accurately predict variables associated with tumor growth, including proliferation, metabolic rate and metastatic potential. In addition, site-specific biomarkers, such as insulin and gastrin, cannot be applied to all types of NENs. The clinical application of broad-spectrum markers, as it is the case for $\mathrm{CgA}$, remains controversial despite being widely used. Due to limitations of the currently available mono-analyte biomarkers, recent studies were conducted to explore novel parameters for NEN diagnosis, prognosis, therapy stratification and evaluation of treatment response. Identification of prognostic factors for predicting NEN outcome is a critical requirement for the planning of adequate clinical management. Advances in 'liquid' biopsies and genomic analysis techniques, including microRNA, circulating tumor DNA or circulating tumor cells and sophisticated biomathematical analysis techniques, such as NETest or molecular image-based biomarkers, are currently under investigation as potentially novel tools for the management of NENs in the future. Despite these recent findings yielding promising observations, further research is necessary. The present review therefore summarizes the existing knowledge and recent advancements in the exploration of biochemical markers for NENs, with focus on gastroenteropancreatic-neuroendocrine tumors.
\end{abstract}

Correspondence to: Mrs. Oana Alexandra Ciobanu, Department of Endocrinology and Diabetes, Elias Hospital, 17 Marasti Avenue, Sector 1, 011461 Bucharest, Romania

E-mail: oana-alexandra.ciobanu@drd.umfcd.ro

Key words: neuroendocrine neoplasms, biomarkers, prognostic markers, liquid biopsies, molecular imaging

\author{
Contents \\ 1. Introduction \\ 2. Aim and search strategy \\ 3. Currently available biomarkers \\ 4. Potential novel biomarkers \\ 5. Conclusions
}

\section{Introduction}

Neuroendocrine neoplasms (NENs) are a heterogenous group of rare malignancies that arise from neuroendocrine cells distributed throughout the body and produce peptide hormones and/or biogenic amines (1). NENs can be dichotomised into 'functional' (F) and 'non-functional' (NF) tumors (2). The F-NENs category represents $33 \%$ of all NENs and is mainly characterized by well-defined clinical symptoms that are caused by the over secretion of their circulating products (2). Examples of F tumors include NENs in the midgut (such as the small intestine), which are classically associated with carcinoid syndrome (CS) due to the overproduction of serotonin (3). Symptoms of CS have been previously reported to be associated with the overproduction of serotonin by F NENs. By contrast, NF NENs are more common in terms of incidence and can cause mechanical symptoms, including ischemia or obstruction, the complications of which from local tumor growth can ultimately result in mortality (2).

Due to the substantial heterogeneity in these NENs both in terms of clinical aggressiveness and response to therapy, management of patients with such diseases is a significant challenge (4). In total, 60-80\% of NENs have already metastasized on diagnosis (5). Prognostic and predictive markers have been intensively investigated to explore the optimal clinical management strategy for this category of neoplasms (6). Investigation into prognostic markers contribute valuable information in understanding the physiology of NENs and their natural course. They reveal beneficial mechanistic information underlying the aggressive properties of the disease and the risk of recurrence or death. By contrast, predictive markers can be used to estimate the benefit of a certain therapy compared with their corresponding condition at baseline, which can assist in implementing the optimal treatment strategy for the most favorable outcome (7). 
At present, the most important prognostic factor for NENs is morphological differentiation characteristics, which can be divided into the well- or poorly-differentiated categories, corresponding to neuroendocrine tumors (NETs) or neuroendocrine carcinomas (NECs) (8). Furthermore, NENs display a varying degree of proliferation known as grade $(\mathrm{G})$, which is approximated using the $\mathrm{Ki}-67$ proliferation index and mitotic count (9). Specifically, the latest 2019 World Health Organization (WHO) classification of gastro-entero-pancreatic (GEP)-NENs distinguishes three grades of NENs that are classified into the low (G1), intermediate-(G2) and high-grade (G3) categories based on the degree of differentiation, with the mention that poorly differentiated NECs are considered definitively G3 $(10,11)$. Although the WHO classification of tumors is considered to be the gold standard tumor classification, it differs depending on their primary site in the body. For example, the 2015 WHO Classification of Tumors of the Lung, Pleura, Thymus and Heart does not make use of the Ki-67 proliferation index (11). However, the current consensus is to improve the management of NENs by adopting an uniformized nomenclature system towards different organs (12). It is hoped that this new classification will serve as a novel grading tool that can be introduced into common clinical practice to reveal essential information regarding NENs (12).

In addition to adequate classification and grading, tumor staging also carries prognostic significance (13). European Neuroendocrine Tumors Society (ENETS) and tumor, nodes and metastases (TNM) classification of the American Joint Committee on Cancer (AJCC) are currently used staging systems that present the classification criteria but are not identical and are site specific $(14,15)$. A number of studies have reported comparative data between the two systems for the classification of pancreatic neuroendocrine tumors (Pan-NETs), suggesting a similar prognosis being found by the two systems in ENETS and TNM of the AJCC, both regarding progression free-survival (PFS) and overall survival (OS) $(16,17)$. However, further studies are needed, as the ENETS staging system appeared to be superior in stratifying prognosis for each stage of pancreatic NENs according to a previous report (18).

However, in terms of the formulation of concrete guidelines for the clinical management of these tumors, numerous issues persist due to the lack of comprehensive databases and registries (9). In addition, an insufficient number of lesion types have been studied despite wide variations in tumor heterogeneity (9). The 5-year survival rate ranges between 15 and $95 \%$, depending on the location of the tumor primary site, the level of metastatic spread at diagnosis, the available treatment options and the geographical site of care (19-21).

Several methods have been reported to predict OS and PFS, including nomograms taking into account the number of liver metastases, tumor size and the Ki-67 index (22), the blood neutrophil-lymphocyte ratio, Ki-67 index and the lymph node ratio (23) or phosphorylated histone H3 (24). However, further research is required.

An important obstacle in clinical practice is the scarcity of a set of sensitive and specific tumor biomarkers (25). The 'perfect' biomarker would ideally be characterized by high sensitivity in diagnosing NENs, good prediction of disease evolution and response to therapy (26). Currently available
NETs biomarkers belong to the mono-analyte class and vary in the rates of sensitivity and specificity for indicating the biological characteristics, such as primary tumor site, or functional or non-functional type secretion. In addition, these mono-analyte measurements are unable to define the state of disease progression or efficacy of therapy (27), which frequently do not correlated well with radiological evaluation data (28). To overcome these shortcomings, interest in the molecular profiling of NENs is increasing. Recent studies have demonstrated the utility of molecular imaging as a viable option for predicting the prognosis of NENs $(29,30)$. Since the density of somatostatin receptors (SSTRs) can also be quantitively assessed using immunohistochemistry (IHC) in the surgical specimens, this can be used to predict treatment response (31-33). Furthermore complementary imaging modalities or early radiological biomarkers, such as the tumor grade rate (TGR), have been proposed to contribute valuable prognostic information $(34,35)$.

Molecular diagnostics have previously been performed on biopsies of solid tumor tissues (13). As one branch of this technique, 'liquid' biopsy is a non-invasive strategy that can provide the opportunity to investigate the molecular genomic mechanism of tumor cells in circulating blood (the 'tumor circulome') to characterize the circulating molecular profiles, which may be useful for subsequent diagnosis and monitoring $(36,37)$. Emerging biochemical and therapeutic markers have become increasingly popular since 2004 and their relevance are expected to increase exponentially by $2050(13,38,39)$. Identifying novel parameters is important for optimally predicting the prognosis and treatment response for each patient. Therefore, the present review summarizes some of the current and future directions in this field of research with an emphasis on GEP-NENs.

\section{Aim and search strategy}

The aim of the present review is to summarize the available data on the diagnostic, prognostic and predictive biomarkers for NENs. The review is structured into the following two parts: i) Discussion of the markers most commonly used in clinical practice at present; and ii) potential future diagnostic, prognostic and predictive biomarkers.

Search strategy. Published data in the SCIENCEDIRECT (https://www.sciencedirect.com/) and PUBMED (https://pubmed.ncbi.nlm.nih.gov/) databases were collected and analyzed. Publications from the past 5 years were prioritized and selected using the following relevant key words either alone or in combination: 'Neuroendocrine neoplasms', 'neuroendocrine tumors', 'biomarkers', 'liquid biopsies' and 'molecular imaging'. Additional studies were identified by reviewing the references of all selected articles, whereas publications from major scientific meetings were searched manually. After the exclusion of 52 duplicates, 353 articles were scanned, following which 99 titles were removed because they didn't satisfy the subject of the present review. We included A total of 254 publications were selected for a full-text evaluation. The inclusion criteria were clinical and practical relevance in the management of NENs. Full articles and English language published original and review papers were included that 
addressed the diagnosis and especially the prognostic and predictive markers in NENs, with different degrees of statistical power due to the rarity of these neoplasms. Exclusion criteria were case reports and publications with abstracts not relevant for the present review were removed (case studies removed, four; publications removed, 129), so that at the end of the selection process, 121 publications were included (Fig. 1).

\section{Currently available biomarkers}

A number of biomarkers are currently applied for the diagnosis of NENs. However, they are frequently not correlated with diagnosis or clinical outcomes, mainly due to sensitivity and specificity issues (Table I).

Chromogranin A ( $C g A)$. Human $\mathrm{CgA}$ is a glycoprotein that belongs to the family of chromogranins and is localized in the secretory granules alongside peptide hormones and catecholamines throughout the neuroendocrine system (40). Recognition of CgA as the default NET biomarker is widely applied over the past decade due to its broad-spectrum nature, with high levels being found in both F and NF NENs (41-43). Yet, $\mathrm{CgA}$ detection and reliability are still based on different non-standardized assays (44). However, Cg A is highly expressed in NETs tissue, but can also be measured in serum or plasma as a widely used circulating tumor marker (40). High levels of $\mathrm{CgA}$ are mainly observed in well-differentiated NETs and are associated with larger tumor burden, especially in gut NETs $(5,45)$. By contrast, CgA suffers from low sensitivity for poorly-differentiated tumors, where its production is less pronounced $(40,46)$.

As a result, enthusiasm for the application of $\mathrm{CgA}$ as a marker is waning, which is compounded by the accumulating evidence of its low utility $(43,47)$. The specific cut-off value (identified by the receiver operating characteristic analysis between different assays) (44), primary location of the NEN (48), endocrine-associated syndrome (5), disease spread, liver metastases (49), false-positive elevations in CgA typically caused by proton pump inhibitors, atrophic gastritis and kidney failure (13), can all influence the accuracy of this test.

However, a recent systematic review and meta-analysis evaluated the role of $\mathrm{CgA}$ in bronchopulmonary NENs because of the scarcity of evidence in this field (43). This previous study reported the clinical utility of $\mathrm{CgA}$ for the diagnosis of lung NENs, especially in small cell lung cancer (SCLC) with a mean diagnostic specificity of $79.5 \pm 3.1$ and sensitivity of $59.9 \pm 6.8 \%$. Still, this finding require further validation (43).

Urinary 5-hydroxyindoleacetic acid (5-HIAA). 5-HIAA is a metabolite of serotonin, which is excessively produced by serotonin-secreting tumors and is excreted in the urine (13). Prior to interpretating the 5-HIAA test measurement in the urine as a result, pharmacological and dietary artifacts must first be ruled out, typically by avoiding the intake of tryptophan- and serotonin-rich foods (50). Measurement of urinary 5-HIAA excretion is more practical for patients with primary midgut (jejunoileal, appendiceal and ascending colon) NETs, which produces the highest levels of serotonin (51). For carcinoid syndrome (CS), this test has a reported sensitivity of $>90 \%$ and a specificity of $90 \%$ (52). Additionally, a level of 5-HIAA

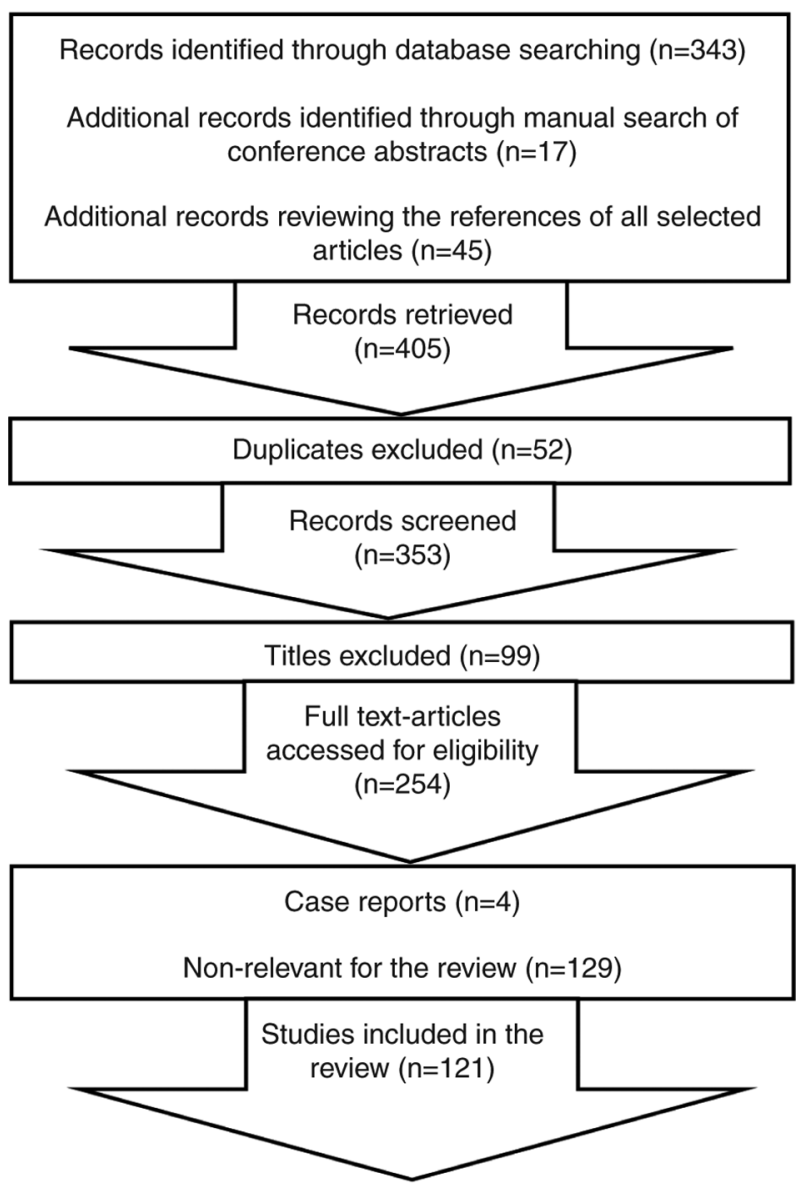

Figure 1. Flow chart for the selection of studies discussed in the present review.

$>300 \mathrm{mmol} / 24 \mathrm{~h}$ and three flushing episodes per day can be considered to be a predictive factor of carcinoid heart disease (CHD) (53). There is also evidence that 5-HIAA in combination with N-terminal probrain natriuretic peptide (NT-proBNP) can be accurately used in screening for CHD (54). Nevertheless, its prognostic role remains controversial.

N-terminal Pro-Brain Natriuretic Peptide (NT-proBNP). NT-pro BNP is a peptide that is released by myocardial cells as a result of an increase in heart volume and pressure and is used especially for CHD prediction, which has been previously correlated with patient survival $(55,56)$. A high sensitivity and specificity for CHD, 92 and $91 \%$, respectively, has been reported at the cut-off value of $260 \mathrm{pg} / \mathrm{ml}$ (57). In addition, measurement of the level of serum NT-proBNP has been recommended for intestinal NENs and CS for the diagnosis and follow-up of CHD (54).

Neuron specific enolase (NSE). NSE is the main enolase-isoenzyme present in neuronal and neuroendocrine tissues (58). Although mainly expressed poorly-differentiated NET cells, measurement of serum NSE cannot be used to distinguish among different subtypes of NENs (59). Consequently, although elevated levels of NSE seems to have a degree of prognostic value for poor outcome and correlate with tumor burden, NSE is now rarely used in clinical practice since it is inferior to $\mathrm{CgA}$ in terms of the information that can be extracted (59). 
Table I. Sensitivity and specificity of current biomarkers.

\begin{tabular}{|c|c|c|c|c|c|}
\hline First author/s, year & Tumor marker & Primary tumor location & Sensitivity $\%$ & Specificity $\%$ & (Refs.) \\
\hline Oberg et al, 2015 & Chromogranin A & Nonspecific & $60-90$ & $<50$ & (2) \\
\hline Feldman, 1986 & $\begin{array}{l}\text { Urinary 5-hydroxyindole } \\
\text { acetic acid }\end{array}$ & Midgut & 70 & 90 & (51) \\
\hline Bhattacharyya et al, 2008 & $\begin{array}{l}\mathrm{N} \text {-terminal probrain } \\
\text { natriuretic peptide }\end{array}$ & $\begin{array}{l}\text { Midgut: carcinoid heart } \\
\text { disease }\end{array}$ & 92 & 91 & $(57)$ \\
\hline Baudin et al, 1998 & Neuron specific enolase & Nonspecific & 33 & 68 & (59) \\
\hline Walter et al, 2012 & Pancreatic polypeptide & Pancreas & No data & 84 & $(60)$ \\
\hline Laskaratos et al, 2017 & $\begin{array}{l}\text { Connective tissue } \\
\text { growth factor }\end{array}$ & $\begin{array}{l}\text { Midgut: right ventricular } \\
\text { dysfunction }\end{array}$ & 88 & 69 & (61) \\
\hline
\end{tabular}

However, NSE is currently applied as the default tumor marker for SCLC diagnosis, prognosis and follow-up, even though elevated levels of NSE can also be found in non-small cell lung cancer (NSCLC) (58).

Pancreatic polypetide (PP). PP is serum marker produced by the neuroendocrine cells of the colon and pancreas (60). PP is considered to be a non-specific marker for NENs, where its levels has a modest degree of accuracy as a diagnostic marker (13). However, it appears that an $>50 \%$ increase in the serum levels of PP in GEP-NETs patients has a direct proportional relationship with the increase in tumor according to RECIST 1.1 criteria on conventional imaging (CT scan \pm MRI scan) imaging (60).

Connective tissue growth factor (CTGF). CTGF is a modular secreted protein that serves an important role in complex biological mechanisms, including angiogenesis, tumorigenesis and wound healing (61). In addition, CTGF can regulate various types of fibrosis formation, such as cardiac fibrosis (62). Therefore, CTGF has a reported sensitivity of $80 \%$ in detecting heart disease (62). For NETs, previous studies have reported that CTGF expression measured in plasma is more likely to be found in small-bowel ileal rather than in bronchial, pancreatic or rectal NETs $(63,64)$. However, a high level of CTGF was found to be an independent predictive factor for right ventricular dysfunction (61).

Ki-67 proliferation index /mitotic count. Mitotic count, $\mathrm{Ki}-67$ index and necrosis are typically used for the grading of NENs (9). While mitotic count is recommended to be reported as mitoses per $\mathrm{mm}^{2}$ area, in clinical practice this process could be affected by limited areas available for counting. On the other hand, $\mathrm{Ki} 67$ is determined using IHC measured in the most mitotically active areas of the pathological specimen, but due to the intratumoral heterogeneity this process can be affected (9). However, this manner of scoring can be time-consuming, which is compounded by the lack of consensus in the optimal method for determining the proliferative rate $(9,65)$. In clinical practice, when there is a discordance between these two types of measurements in assigning the grade, higher 'grade counts' are normally negatively associated with poorer prognosis (65-67). For example, in $\sim 33 \%$ of well-differentiated Pan-NETs, a G1 grade is determined based on the mitotic count, whereas the G2 grade is determined using the Ki-67 proliferation index (66). In addition, the same percentage $(33 \%)$ of G2 Pan-NETs are found for after mitotic count, but G3 according to the $\mathrm{Ki}-67$ proliferation index (64). Therefore, the use of Ki-67 IHC staining is essential for accurately grading well-differentiated NETs $(65,66)$

The latest 2019 WHO classification of GEP-NENs $(10,67)$ now recognizes the category of high-grade tumors as those with a Ki-67 index of $>20 \%$, of which well-differentiated GEP-NENs represent $\leq 7 \%$ of all NENs (68). In addition, tumor grade based on the Ki-67 index cut-off values has been demonstrated to correlate with patient survival independent of tumor stage in primary and metastatic GEP-NENs $(69,70)$ In particular, the $\mathrm{Ki}-67$ index has also been considered to be a viable prognostic marker for recurrence after the resection of PanNETs (71). In liver metastases, the Ki-67 index has a predisposition to be higher compared with that in primary GEP-NETs, where a proportional relationship between the size of the metastasis and the Ki-67 index was found (72-74)

In clinical practice, detection of multiple primary tumors, multiple lymph node metastases and/or multiple distant metastases are recommended for evaluating tissue blocks with the biggest focus of tumor due to the intratumoral heterogeneity (75). Furthermore, the Ki-67 index may present a variability during the course of the disease or between primary tumor and metastasis (76). In a previous study, the Ki-67 index was evaluated in 103 GEP-NETs, of which $24 \%$ presented with higher grades in the metastasis, $10 \%$ with higher grades in the primary tumor and $66 \%$ with same grade between the metastasis and the primary tumor (77). The PFS and OS were found to be identical for both G1 primaries and G2 metastasis categories, and also for G2 primaries and metastasis; however, these are worse compared with the G1 primary tumors only (G1 stable category). Therefore, any G2 tumors (in primary or in metastases of NETs) influences patient survival.

The Ki-67 index also hold promising potential for clinical application in NECs, since a Ki-67 index with a 55\% cut-off for response was found to be associated with poorer prognosis, favorable response to platinum-based chemotherapy (CHT) (78) and adverse reactions to temozolomide CHT (79). 


\section{Potential novel biomarkers}

The current demand in this field is to improve the methodology for the diagnosis, treatment and prognosis of NENs. Therefore, novel markers have been evaluated over the past decade.

Genetic mutations. Recent studies have benefited from advances in sequencing technology for characterizing the complex molecular landscape of NENs $(80,81)$. Regarding PanNETs, the current trend is mainly focused on determining the roles of multiple endocrine neoplasia 1 (MENI), death-domain associated protein (DAXX), $\alpha$-thalassemia and mental retardation syndrome $X$-linked (ATRX) genes in the alternative lengthening of telomeres (ALT) axis and components in the mTOR and DNA damage pathways $(82,83)$. In particular, molecular alterations have been consistently associated with the following four events: DNA damage repair; cell cycle regulation; PI3K/AKT/mTOR signaling; and telomere maintenance (84).

$D A X X$ and ATRX expression and ALT. Recent studies have revealed increasingly consistent findings despite the lower mutation burden of PanNETs (82) as mutations in the MEN1, $A T R X$ and $D A X X$ genes were frequently observed in this type of tumors (85-87). In total, up to $40 \%$ of well-differentiated NENs in the pancreas exhibit somatic mutations in the DAXX and ATRX genes (82). These two genes encode proteins that interact and have multiple cellular functions, including modulating telomeric chromatin. $A T R X$ and $D A X X$ interact to deposit histone H3.3-containing nucleosomes in the centromeric and telomeric regions of the genome and may interact to suppress the ALT pathway under normal circumstances $(88,89)$. ATRX/DAXX mutations result in loss of nuclear expression of their proteins, as detected by IHC, in tumor tissue, which correlates with the suppression of ALT (90). A negative expression of ATRX/DAXX is typically associated with well-differentiated NENs, and correlate with worse survival in Pan-NETs $(90,91)$. ALT is a telomerase-independent telomere maintenance mechanism that has been previously studied using fluorescence in situ hybridization (92). Altered telomeres are a key process frequently found in PanNETs (93). As such, positive ALT status in liver metastases of NENs was found to associate with worse survival and increased risk of recurrence $(94,95)$. It has been previously shown that there is $100 \%$ concordance among the ALT phenotype, ATRX/DAXX mutations and/or protein loss (92), where the presence of ALT-positive and ATRX/DAXX-negative (inactivation mutation) in well-differentiated PanNETs is associated with a significantly higher grade, size, grading, vascular/perineural invasion, metastatic disease and with reduced relapse-free and tumor-specific survival (96). Therefore, this profile can be applied as a marker of more aggressive PanNET phenotypes for patient stratification $(97,98)$.

Application of fine-needle aspiration (FNA) makes it possible to detect the loss of ATRX/DAXX and the presence of ALT as a non-invasive method to sample tumors. As aforementioned, somatic mutations of ATRX/DAXX genes can be detected using IHC to indicate a loss of nuclear expression of their respective proteins (90). In addition, ALT can be assessed using telomere-specific fluorescence in situ hybridization (92).
This procedure is becoming increasing important in clinical practice, through which ALT or the loss of ATRX or DAXX expression can be verified with higher degrees of confidence during the prognostic process (92).

mTOR signaling pathway. Somatic gene alterations are currently studied in PanNETs $(98,99)$, of which two processes have been frequently observed to be affected chromatin remodeling and activation of PI3K/Akt/mTOR signaling (100). The mTOR pathway regulates cell proliferation, cell cycle and apoptosis; however, in tumor cells, an abnormal activation of mTOR pathway influences the tumor to grow and metastasize (101). Since $14.7 \%$ of PanNET cases exhibit mutations in the PI3K/Akt/mTOR pathway, this finding that can be exploited to select patients for treatment with mTOR inhibitors $(100,102)$.

Mutations in the tuberous sclerosis complex 2 (TSC2) and PTEN genes are suppressors of the Akt/mTOR pathway, which are present in up to $11 \%$ of sporadic PanNETs (100). Reduced expression of both PTEN and TSC2 was found to be associated with more aggressive phenotypes, presence of liver metastases and reduced disease-free survival and OS in a cohort of 72 primary PanNETs according to microarray analysis (99). However, further studies are warranted before mutations of components in the PI3K pathway can be considered as a biomarker of response.

Retinoblastoma protein 1 (RB1) and p53 in NECs but not in NETs. The most recent 2019 WHO classification of GEP-NENs made a clear distinction between NET G3 and NEC (10). NET G3 lacks consensus-based recommendations is associated with longer OS (98). In certain cases, histology is not sufficient for differentiating between highly proliferative NETs and NECs (103), where it is hoped that molecular profiling can amend this deficiency. Abnormal immunolabeling of $p 53$ and $R B 1$ pathways are currently being proposed for the distinction of well-differentiated NETs, especially NETs G3 from poorly differentiated NECs during diagnosis (103). Although p53 and RB1 are considered to be two key drivers of NECs, but in NETs these mutations are rarely observed (104-107). Double inactivation of the TP53 and RBI genes is one of the genetic signatures of SCLC (108). The presence of these inactivated mutations is used as a predictive marker of the response to platinum-based CHT in lung and GEP-NECs $(104,105,108)$. In addition, the loss of $R B 1$ is associated with superior responses to platinum salts in both lung and pancreas NECs $(104,109)$, whilst the presence of $p 53$ staining in colorectal NECs is associated with weaker responses to platinum-based $\mathrm{CHT}$ and worse prognosis (105). In GEP-NECs, p53 IHC is currently under examination as a possible diagnostic, prognostic and predictive method for GEP-NECs, which was reported in several studies with frequencies of $p 53$ immunoreactive cells ranging from $20-100 \%$ (103), where mutations in TP53 associates poor survival, moreover TP53 being the most prevalent mutation in NECs $(105,110)$.

\section{Expression markers}

Insulinoma-associated protein 1 (INSM1). INSM1 is a zinc-finger family of transcription factors that serves a role in neurogenesis and neuroendocrine cell differentiation (111). 
INSM1 confers certain advantages in NECs as it more sensitive compared with traditional general neuroendocrine markers, such as $\mathrm{CgA}$ or synaptophysin, since the clear nuclear expression pattern of INSM1 facilitates its accurate interpretation and quantification whilst reducing the incidence of staining artifacts (65).

The Notch/hairy and enhancer of split-1 (Hes-1) signaling pathway serves a key role in tumor growth and development, which has also been reported to inhibit INSM1 (112). INSM1 has recently been reported to be an important biomarker in the diagnosis of SCLC as it serves as an important factor in ASCL1-driven pathways. ASCL1 is needed for the protein expression of NE molecules and in the development of lung NE cells $(113,114)$. Furthermore, functional interactions between ASCL1 and the Notch1-Hes1 pathway have been reported (113). As aforementioned, the Notch1-Hes1 pathway is involved in the suppression of INSM1 expression (112). Moreover, the implication of INSM1 suppression is being studied as a modulator factor in PanNETs, which could be connected to the Notch1-Hes1 signaling pathway $(112,115)$.

Tanigawa et al (112) revealed that INSM1 expression was positive in all cases of PanNETs but negative in cases of pancreatic ductal adenocarcinoma (PDAC), rendering it a potential marker for distinguishing between PanNETs and PDAC. In addition, INSM1 has also been found to be a potential marker for SCLC, since a number of studies reported that INSM1 expression was present in 97-100\% SCLC cell lines, which appeared to be more sensitive and specific compared with $\mathrm{CgA}$ and 1-3,4-dihydroxyphenylalanine decarboxylase $(111,113)$. Furthermore, recent studies reported the superior sensitivity of INSM1 for the diagnosis of NENs regarding their neuroendocrine origin (65,116). Bellizzi et al (65) studied a cohort of 93 NECs, where $95 \%$ sensitivity was found for INSM1 compared with 83 and $82 \%$ for CgA and synaptophysin, respectively.

NETest-a transcriptomic signature of NETs. The NETest uses multianalyte assays with algorithmic analyses (MAAAs), which is a novel method including procedures that incorporate results derived from multiple assays and can increase both the sensitivity and specificity (117). This assay involves mRNA isolation, cDNA synthesis followed by the subsequent quantitative-PCR measurement of 51 circulating NET marker genes (117). These genes were chosen based on the analyzed microarray datasets containing the cellular profiles of fresh frozen tumor samples and whole blood samples from patients diagnosed with NET to characterize the expression patterns (117). Finally, a multi-analyte liquid biopsy representative for NETs was used to determine the biological activity of the tumor and therefore clinical status of the patient (118). Results are presented as the numeric score (NET score) that include the following three categories: i) Low, $\leq 21-40 \%$; ii) intermediate, $41-79 \%$; and iii) high (biologically aggressive), $\geq 80 \%$. The PCR test is standardized and reproductible; moreover, diet, proton pump inhibitors medication, age, sex and ethnicity do not interfere with the accuracy of the test $(119,120)$. In addition, MAAA is reproducible at multiple time points, which provides real-time NET scores $(118,120)$.

In a cohort of 100 patients with three different types of tumors (GEP, lung bronchopulmonary NETs and unknown origin tumors), the NETest test had a reported diagnostic sensitivity of $96 \%$, which was $>90 \%$ effective in combination with diagnostic imaging for guiding treatment decisions (121). This previous study also demonstrated that a low NET score $(\leq 40 \%)$ was associated with superior outcomes, where the PFS was not reached, whilst intermediate to high NETest scores (41-100\%) were associated with significantly shorter PFS and treatment failures (121). In addition, the NETest has been documented to be a useful tool for the detection of lung, thymic, pancreatic and gastrointestinal tract NETs, as well as paragangliomas and pheochromocytomas with $\geq 90 \%$ accuracy (39). Moreover, the NETest can predict aggressive tumor behavior in other NENs $(122,123)$, or the outcome following tumor resection and efficacy of medical treatments, such as somatostatin analogues (SSAs) or peptide receptor radionuclide therapy (PRRT) (39).

A recent meta-analysis was conducted to assess the eligibility of NETest as a biomarker tool in the field of oncology (124). The results supported the utility of this test as a diagnostic tool for GEP and bronchopulmonary NETs, which reported an accuracy of $85 \%$ in differentiating between stable and progressive disease whereas a specificity of $\sim 90 \%$ was reported (124).

Aristaless related homeobox $(A R X) /$ pancreatic and duodenal homeobox 1 (PDXI) expression. ARX and PDX1 are regulatory proteins involved as epigenetic modifiers in pancreatic development (86). The assessment of ARX/PDX1 expression has been previously studied as a potential pre-operative risk stratification marker for PanNETs (125). Since $>50 \%$ PanNETs already have liver metastases at first presentation, novel strategies are emerging for the other $50 \%$ with aims to reduce the risk of metastasis (126). Although the choice of surgery for the primary tumor can reduce the risk of metastasis, it is also associated with increased risk of post-surgery morbidity and mortality. Therefore, apart from tumor size, transcription factors ARX and PDX1 alongside ATRX/DAXX mutations and the status of ALT were studied as prognostic markers in resected NF PanNETs (96). Cytological specimens of PanNETs obtained by endoscopic FNA was previously studied using the IHC staining of ARX, PDX1 and telomere-specific fluorescence in situ hybridization to detect ALT (125). Positive ALT activity and ARX expression in the tumor coupled with negative PDX1 staining was documented to predict metastatic phenotype for the stratification of patients into the low- or high-risk groups preoperatively (125).

MicroRNA (miRNA or miR) markers. miRNAs are a class of RNAs that do not encode protein and are 22 nucleotides in length (127). They typically regulate post-transcriptional gene expression by targeting mRNA molecules (127). Circulating miRNAs can be used as minimally invasive biomarkers of ovarian, cervical or breast cancer as they are readily detectable in a wide variety of biofluids, including plasma, serum and saliva (128).

The global microRNA expression patterns were studied in normal pancreas, PanNETs and acinar carcinomas in order to assess the role of microRNAs in malignant transformation and progression (129). miR-103 and miR-107 expression levels were found to be higher whereas the level miR-155 expression was lower in PanNETs compared with the normal 
pancreas (129). Furthermore, miR-21 expression level appears to be higher in the plasma of patients with PanNETs compared with that in patients with chronic pancreatitis (129). Therefore, it can be applied both as a diagnostic and a prognostic tool for PanNETs, since higher levels of miR-21 expression and high $\mathrm{Ki}-67$ proliferation index were associated with the presence of metastases $(129,130)$.

It was recently reported that in tumors without a known primary site, miRNA expression can be used to facilitate diagnosis (131). miRNA expression profiles were previously analyzed in four pathological types of GEP-NETs, including samples from pancreatic, ileal, appendiceal and rectal NETs (131). The results were promising, as the midgut NETs (ileum and appendix) could be discriminated from non-midgut NETs (rectum, pancreas) according to miR-615 and miR-92b expression (131). In addition, ileal NETs could be discriminated from appendiceal NETs according to miR-125b, miR-192 and miR-149 expression, whilst rectal NETs could be distinguished from pancreatic NETs based on miR-429 and miR-487b expression (131).

Due to their stability in the circulation and abundance, cell-type and disease stage specificity and their reported roles in a number of biological processes, miRNAs have been investigated in various studies. However, due to the lack of consistency in the reported signatures (between results that used tissue and those that used circulating blood) for the same disease and the lack of standardization methods with accurate techniques, further research is required $(132,133)$.

Methylation markers. Epigenetic events occur depending on the subtype of NETs (134). DNA hypermethylation is an early event that frequently occurs during cancer initiation and can dictate the rate of disease development and progression (135). The 'Hypermethylation phenotype' was associated with poorer OS and with more progressive disease in PanNETs (135).

O-6-methylguanine-DNA methyltransferase (MGMT) for NETs but not for NECs. The role of the MGMT enzyme is to repair DNA lesions as a result of alkylating agents usually used in NENs. Loss of MGMT function occurs as a result of epigenetic events, such as hypermethylation, of the MGMT gene promoter (136). This in turn leads to the loss of MGMT protein expression, which can be detected using IHC or detected on the gene level by methylation analysis (for example using methyl-specific PCR or pyrosequencing). Analysis of the MGMT status can be used to predict the prognosis and response to alkylating agents that induce DNA damage in well-differentiated NENs (107). Previous studies showed that reduced MGMT expression is associated with increased rates of treatment response to temozolomide, dacarbazine and streptozotocin CHT in digestive and lung NENs $(136,137)$.

\section{Circulating biomarkers}

Cell-free DNA ( $f D N A)$. The importance of tumor-specific alterations in cell-free DNA (cfDNA) in liquid biopsies is becoming increasingly recognized, which can either complement or replace tissue biopsies for several types of cancer, including NSCLC with mutations in the EGFR gene $(138,139)$. cfDNA consists of a proportion of circulating tumor DNA (ctDNA) in the blood plasma, which originates from the tumor following apoptosis, necrosis and active secretion $(140,141)$. cfDNA can be used as a biomarker for cancer, as patients with patients are reported to have greater levels of plasma cfDNA compared with tumor-free controls (142); in addition, high levels of cfDNA are also described in other diseases, such as autoimmune disorders (143). However, further studies in NENs are required to verify the utility of cfDNA as a profiling tool. Boons et al (141) first reported that the presence of ctDNA through the identification of copy number variations and tumor specific point mutations using shallow whole genome sequencing and droplet digital PCR, respectively can be used to differentiate between metastatic and localized PanNET. The results of this study demonstrated that ctDNA is found in the plasma samples of patients with metastatic disease. This was shown by tumor-specific variants that were obtained through whole exome sequencing (WES) analysis of primary tumor tissue and germline DNA, in comparison with localized PanNETs where when genotyping variants in cfDNA, the variants could not be detected. Therefore, cfDNA is a candidate as an alternative biomarker to tissue biopsies for molecular profiling.

Circulating tumor cells (CTCs). CTCs are typically released into the blood of patients who have undergone epithelial and mesenchymal transition, which cause metastatic disease $(13,144)$. The presence of CTCs at the moment of recruitment/initial evaluation in the blood samples of patients with midgut, pancreas, bronchopulmonary and of unknown primary metastatic NENs was previously associated with worse PFS and OS (145). In addition, CTCs are associated with higher tumor grades and burden, high levels of $\mathrm{CgA}$ and higher Ki-67 indices in G1 and G2 midgut and pancreatic NETs (146). Their potential predictive role was previously studied in a cohort of 138 patients with metastatic NENs, where $41(29.7 \%)$ received long-term SSAs. Changes in repeat CTC count at 3-5 weeks after initiation of therapy were associated with both progressive disease and OS (147). Improved survival was recorded in patients who did not have CTCs at baseline and after therapy in addition to those who presented with $>50 \%$ CTC reduction after treatment (147). However, CTC lacks sensitivity and specificity as a diagnostic tool for different types of NENs (13). This limitation is currently under investigation in a multicenter, exploratory CalmNET phase IV study (ClinicalTrials.gov Identifier, NCT02075606), which is monitoring a relatively homogeneous group of patients with F G1-G2 midgut NETs treated with lanreotide autogel. This study is attempting to evaluate the predictive power of CTC count on clinical outcome, PFS and quality of life (148).

\section{Molecular imaging as biomarkers}

Somatostatin receptors agonists. Expression of SSTR in the majority of NENs, particularly subtype 2, can be imaged by labelling SSAs with a radionuclide, which is typically ${ }^{68} \mathrm{Ga}$, using a chelate, such as 1,4,7,10-tetraazacyclododecane-1,4,7,1 0 -tetraacetic acid (DOTA) $(149,150)$.

At present, two types of molecular imaging that can be used to target SSTR in clinical practice: ${ }^{111}$ In-pentetreotide (OctreoScan) and ${ }^{68} \mathrm{Ga}$-DOTA-Phe ${ }^{1}-\mathrm{Tyr}^{3}$-Octreotide (TOC), ${ }^{68} \mathrm{Ga}-\mathrm{DOTA}-\mathrm{NaI}^{3}$-Octreotide (NOC) or ${ }^{68} \mathrm{Ga}$-DOTA-Tyr ${ }^{3}$-Octreotate (TATE). ${ }^{68} \mathrm{Ga}$-DOTATATE/TOC/NOC-PET/CT confers higher scanner 
sensitivity, superior spatial resolution and require lower radiation doses (151). Although all three radiotracers (DOTA-TOC, DOTA-NOC and DOTA-TATE) have good affinity for SSTR types 2 and 5, ${ }^{68} \mathrm{Ga}$-DOTA-NOC exhibits higher affinity for SSTR type 3 (152). However, ${ }^{68} \mathrm{Ga}$-DOTA-TATE confers superior diagnostic precision for the nuclear imaging of NENs and is currently used in USA, whilst ${ }^{68} \mathrm{Ga}$-DOTA-TOC-PET is mainly used clinically in the European Union $(153,154)$.

${ }^{68} \mathrm{Ga}$-DOTA-TATE-PET has previously demonstrated its superiority over Octreoscan for the location of primary GEP-NETs, with a $95.1 \%$ detection rate compared with 30.9 and $45.5 \%$ from other conventional imaging modalities, respectively (155). This outcome changed the medical recommendation in $32.8 \%$ of the patients (155). Results from ${ }^{68} \mathrm{Ga}$-DOTA-TOC-PET/CT imaging also demonstrated a high affinity to SSTR2 expression derived from IHC and can serve as a predictive marker for patient response to treatment with PRRT $(156,157)$. In addition, ${ }^{68} \mathrm{Ga}$-DOTA-TOC-PET/CT can be used to select patients who may potentially benefit from SSAs and PRRT, as a high tumor uptake of ${ }^{68} \mathrm{Ga}$-DOTA-TOC-PET/CT can be useful in the treatment selection of the patients (158).

PRRT is a key second-line treatment option for G1 or G2 midgut NETs with disease progression on SSA treatment (91). PRRT can be used to identify radiation delivered by radionuclides, such as lutetium-177 $\left({ }^{177} \mathrm{Lu}\right)$ or yttrium-90 $\left({ }^{90} \mathrm{Y}\right)$, to NET cells following internalization after binding to SSTR (151). However, the expression of SSTRs is currently being studied as a predictive marker for treatment response (13). In the NETTER-1 prospective randomized phase 3 clinical trial (ClinicalTrials.gov Identifier, NCT01578239), ${ }^{177}$ Lu-DOTA-TATE demonstrated its superiority compared with high-dose octreotide in prolonging the PFS in patients with midgut NETs (PFS at month 20, 65.3\% for ${ }^{177}$ Lu-DOTATATE; $10.8 \%$ for high-dose octreotide group) (159).

Somatostatin receptors antagonists. Higher tumor uptake of radiolabeled somatostatin receptor antagonists their potential role has been studied for diagnostic and therapeutic approach in NETs (160). Previous studies reported higher sensitivity and diagnostic accuracy with increased image contrast for ${ }^{68} \mathrm{Ga}-N O D A G A-J R 11$ (68Ga-OPS202), a SSTR-2 antagonist, compared with agonists ${ }^{68} \mathrm{Ga}$-DOTA-TATE and ${ }^{68} \mathrm{Ga}$-DOTA-TOC, for staging G1 and G2 GEP-NETs (ClinicalTrials.gov identifier, NCT02162446) (160,161). A 'theragnostic pair'- ${ }^{68} \mathrm{Ga} /{ }^{177} \mathrm{Lu}-\mathrm{DOTA}-J R 11$ combination was also investigated in a single-center study (ClinicalTrials.gov identifier, NCT02609737). Although there are indications that it binds to more cell types compared with DOTA-TATE or DOTA-TOC in low-grade NETs, this investigation remain in progress at present. Similarly, a peptide ligand, ${ }^{68} \mathrm{Ga}$-DOTA-bombesin, which can bind to the gastrin realizing peptide receptor in prostate cancer cells (162), is another example of this receptor system that is under evaluation for NENs. Its first application for PET imaging in humans for prostate and breast cancer has been previously reported (162).

${ }^{18} \mathrm{~F}$-fluoro-deoxyglucose (FDG)-PET/CT $\left({ }^{18} \mathrm{~F}-\mathrm{FDG}\right.$-PET/CT). ${ }^{18} \mathrm{~F}-\mathrm{FDG}-\mathrm{PET} / \mathrm{CT}$ avidity, especially for detecting G3 NET, was reported to be an indirect marker of proliferative activity in the tumor, showing a higher sensitivity $(87.5 \%)$ than somatostatin receptor scintigraphy $(87.6 \%)$ for detecting rapidly progressive disease (163). In a retrospective study, ${ }^{18} \mathrm{~F}$-FDG avidity was measured quantitatively as a potential prognostic marker in a cohort of 89 patients with metastatic GEP-NETs (164). These patients were divided into three groups based on the ratio of standardized uptake value (SUV) max of the lesion that had the highest FDG uptake as compared to normal liver uptake of FDG (tumor-to-liver T/L SUV ratio) (ratio $\leq 1,1-2.3$ and $>2.3$ ). These three categories associated positively with OS (median OS not reached after 114 months for patients with T/L SUV ratio $\leq 1$ vs. 55 months for patients with T/L SUV ratio of 1-2.3 vs. 13 months for patients with T/L SUV ratio >2.3) (164).

NET-PET score. Somatostatin receptor imaging (SRI) is currently considered the gold standard for detecting well-differentiated NETs. However, it has a number of limitations for detecting high grade NETs due to the possibility of false-negatives, since these types of tumors do not express SSTRs (156). Although ${ }^{18} \mathrm{~F}-\mathrm{FDG}$-PET can be used for staging G3 NECs, it is more suited for predicting the prognosis of well-differentiated NETs, where higher levels of uptake were associated with an increased risk of early progression (163). By contrast, lower levels of uptake is associated with a less aggressive phenotype of the tumor (163). Chan et al (165) therefore proposed a grading system combining these two nuclear imaging techniques (SRI and ${ }^{18} \mathrm{~F}$-FDG-PET) as a single parameter, named 'NET-PET', which was found to associate with OS. This scoring system is designated into five risk category groups: i) Grade $\mathrm{P} 0$, negative uptake for both scans; ii) grade P1, purely STTR-positive lesions without FDG uptake above background; iii) grades P2-P4, intermediate categories; and iv) grade P5, presence of significant FDG-positive/STTR-negative disease (166). The NET-PET score may influence the initial management method of patients with well-differentiated metastatic midgut NET, since the ENETS guideline (167) recommends CHT or SSA as the first-choice treatment option. During the initial phases of SSA therapy, there is no consensus on the upper cut-off value of the Ki-67 proliferation index (165). In this case, the NET-PET score would favor SSA treatment if there is high SRI uptake and low FDG uptake, whilst the contrary would favor CHT (168). The same line of reasoning can be made during patient selection for PRRT, where high SRI uptake but low FDG uptake would suggest PRRT as a viable treatment option, whilst higher FDG uptake and low SRI uptake would indicate likelihood of PPRT resistance (169). Since this was a retrospective analysis, it remains to be elucidated how the individual intermediate classifications can influence the prognosis and treatment decision in a prospective study.

Tumour growth rate as an early biological marker. Accumulating data suggest that the response evaluation criteria in solid tumors (RECIST 1.1) has several limitations in predicting the response to different types of systemic treatments (ST) $(34,170)$. According to RECIST 1.1, the majority of patients with G1-2 GEP-NETs would be classified as having 'stable disease' (170). However, even non-responders can survive for a long period without disease progression, since it is known that well-differentiated GEP-NETs have a relatively 
slow growth rate (34). Therefore, is important to discover a tumor marker that can identify patients who are at high risk of disease progression at the early stage (171). Previous studies reported TGR to be a dynamic marker, which analyzes images from two examinations and the time between the examinations and can reveal beneficial quantitative information regarding the percentage of change in the tumor volume each month $(171,172)$. The GREPONET I study confirmed that the TGR measured at 3 months $\left(\mathrm{TGR}_{3 \mathrm{~m}}\right.$ ) after starting ST or watch and wait (WW) treatment with a cut-off of $0.8 \% / \mathrm{m}$ ( $\mathrm{m}$, percentage of the change of the tumor size in one month), could be used in clinical practice to monitor the treatment response in NETs for the early prediction of PFS (34). In addition, an increased $\mathrm{TGR}_{3 \mathrm{~m}}(\geq 0.8 \% / \mathrm{m})$ was found to associated with shorter PFS, whilst a decreased $\mathrm{TGR}_{3 \mathrm{~m}}(<0.8 \% / \mathrm{m}-)$ was found to associate with longer PFS (34). This finding suggests that patients with high $\mathrm{TGR}_{3 \mathrm{~m}}$ should be followed up more regularly, whilst those with lower $\mathrm{TGR}_{3 \mathrm{~m}}$ can receive imaging less regularly to avoid unnecessary radiation (34). Subsequently, the GREPONET II study explored whether beginning any ST including WW can induce any changes in TGR, which was defined as $\mathrm{TGR}_{3 \mathrm{~m}}-\mathrm{TGR}_{0}\left(\mathrm{TGR}_{0}\right.$ was calculated by comparing the baseline and imaging examination performed within 1 year before the baseline scan) (35). Since it was expected that TGR can be used for monitoring treatment change with no impact on PFS, further study is required.

\section{Conclusions}

Selection of the optimal treatment option for patients with NEN is difficult due to the heterogeneity in the tumor physiology and varying degrees of aggressiveness. There is a demand for multidisciplinary tumor management guidelines driven by data derived from modern radiology and molecular profiling techniques, to inform the optimal medical decision. Overall, further studies integrating a combination of markers based on tumor genomics and a large spectrum of radiological techniques, such as molecular imaging, would be better placed for shaping the future of clinical NEN research. The present review highlights the importance of a second opinion for improving the method of prognostic stratification and choice of personalized treatment strategies.

\section{Acknowledgements}

Not applicable.

\section{Funding}

No funding was received.

\section{Availability of data and materials}

Not applicable.

\section{Authors' contributions}

OAC wrote the literature review. SF and SM critically reviewed the manuscript. Data authentication is not applicable. All authors read and approved the final manuscript.

\section{Ethics approval and consent to participate}

Not applicable.

\section{Patient consent for publication}

Not applicable.

\section{Competing interests}

The authors declare that they have no competing interests.

\section{References}

1. Klöppel G: Neuroendocrine neoplasms: Dichotomy, origin and classifications. Visc Med 33: 324-330, 2017.

2. Oberg K, Modlin IM, de Herder W, Pavel M, Klimstra D, Frilling A, Metz DC, Heaney A, Kwekkeboom D, Strosberg J, et al: Consensus on biomarkers for neuroendocrine tumour disease. Lancet Oncol 16: e435-e446, 2015.

3. Cheung VTF and Khan MS: A guide to midgut neuroendocrine tumours (NETs) and carcinoid syndrome. Frontline Gastroenterol 6: 264-269, 2015.

4. Pedraza-Arévalo S, Gahete MD, Alors-Pérez E, Luque RM and Castaño JP: Multilayered heterogeneity as an intrinsic hallmark of neuroendocrine tumors. Rev Endocr Metab Disord 19: 179-192, 2018.

5. Modlin IM, Gustafsson BI, Moss SF, Pavel M, Tsolakis AV and Kidd M: Chromogranin A-biological function and clinical utility in neuro endocrine tumor disease. Ann Surg Oncol 17: 2427-2443, 2010

6. Zatelli MC, Grossrubatscher EM, Guadagno E, Sciammarella C, Faggiano A and Colao A: Circulating tumor cells and mirnas as prognostic markers in neuroendocrine neoplasms. Endocr Relat Cancer 24: R223-R237, 2017.

7. Sechidis K, Papangelou K, Metcalfe PD, Svensson D, Weatherall $J$ and Brown G: Distinguishing prognostic and predictive biomarkers: An information theoretic approach. Bioinformatics 34: 3365-3376, 2018.

8. Lloyd RV, Osamura RY, Klöppel G and Rosai J (eds): WHO Classification of Tumours of Endocrine Organs. 4th edition, Volume 10. Lloyd RV, Osamura RY, IARC, 2017.

9. Rindi G, Klimstra DS, Abedi-Ardekani B, Brambilla E, Asa LS, Bosman TF, Busam JK, Dietel M, Fernandez-Cuesta L, Sasano $\mathrm{H}$, et al: A common classification framework for neuroendocrine neoplasms: An International Agency for Research on Cancer (IARC) and World Health Organization (WHO) expert consensus proposal. Mod Pathol 31: 1770-1786, 2018.

10. Nagtegaal ID, Odze RD, Klimstra D, Paradis V, Rugge M, Schirmacher P, Washington KM, Carneiro F and Cree IA; WHO Classification of Tumours Editorial Board: The 2019 WHO classification of tumours of the digestive system. Histopathology 76: 182-188, 2020.

11. Travis WD, Brambilla E, Nicholson AG, Yatabe Y, Austin JHM, Beasley MB, Chirieac LR, Dacic S, Duhig E, Flieder DB, et al: The 2015 World Health Organization classification of lung tumors: Impact of genetic, clinical and radiologic advances since the 2004 classification. J Thorac Oncol 10: 1243-1260, 2015

12. Rindi G and Inzani F: Neuroendocrine neoplasm update: Toward universal nomenclature. Endocr Relat Cancer 27: R211-R218, 2020.

13. Herrera-Martínez AD, Hofland LJ, Gálvez Moreno MA, Castaño JP, de Herder WW and Feelders RA: Neuroendocrine neoplasms: Current and potential diagnostic, predictive and prognostic markers. Endocr Relat Cancer 26: R157-R179, 2019.

14. Rindi G, Klöpper G, Alhman H, Caplin M, Couvelard A, de Herder WW, Eriksson B, Falchetti A, Falconi M, Komminoth $\mathrm{P}$, et al: TNM staging of foregut (neuro)endocrine tumors: A consensus proposal including a grading system. Virchows Arch 449: 395-401, 2006.

15. Rindi G, Klöpper G, Couvelard A, Komminoth P, Körner M, Lopes JM, McNicol AM, Nilsson O, Perren A, Scarpa A, et al: TNM staging of midgut and hindgut (neuro) endocrine tumors: A consensus proposal including a grading system. Virchows Arch 451: 757-762, 2007. 
16. Cho JH, Ryu JK, Song SY, Hwang JH, Lee DK, Woo SM, Joo YE, Jeong S, Lee SO, Park BK, et al: Prognostic validity of the American joint committee on cancer and the European neuroendocrine tumors staging classifications for pancreatic neuroendocrine tumors: A retrospective nationwide multicenter study in South Korea. Pancreas 45: 941-946, 2016.

17. Strosberg JR, Cheema A, Weber J, Han G, Coppola D and Kvols LK: Prognostic validity of a novel American Joint Committee on Cancer Staging Classification for pancreatic neuroendocrine tumors. J Clin Oncol 29: 3044-3049, 2011.

18. Rindi G, Falconi M, Klersy C, Albarello L, Boninsegna L, Buchler WM, Capella C, Caplin M, Couvelard A, Doglioni C, et al: TNM staging of neoplasms of the endocrine pancreas: Results from a large international cohort study. J Nat Cancer Inst 104: 764-777, 2012.

19. Gustafsson BI, Kidd M, Chan A, Malfertheiner MV and Modlin IM: Bronchopulmonary neuroendocrine tumors. Cancer 113: 5-21, 2008.

20. Yao JC, Hassan M, Phan A, Dagohoy C, Leary C, Mares JE, Abdalla EK, Flemming JB, Vauthey IN, Rashid A and Evans DB: One hundred years after 'carcinoid': Epidemiology of and prognostic factors for neuroendocrine tumors in 35,825 cases in the United States. J Clin Oncol 26: 3063-3072, 2008.

21. Garcia-Carbonero R, Capdevila J, Crespo-Herrero G, Díaz Pérez JA, Martínez Del Prado MP, Alonso Orduña V, Sevilla-García I, Villabona-Artero C, Beguiristain-Gómez A, Llanos-Muñoz M, et al: Incidence, patterns of care and prognostic factors for outcome of gastroenteropancreatic neuroendocrine tumors (GEP-NETs): Results from the National cancer registry of Spain (RGETNE). Ann Oncol 21: 1794-1803, 2010 .

22. Ruzzenente A, Bagante F, Bertuzzo F, Aldrighetti L, Ercolani G, Giuliante F, Ferrero A, Torzilli G, Grazi GL, Ratti F, et al: A nove nomogram to predict the prognosis of patients undergoing liver resection for neuroendocrine liver metastasis: An analysis of the Italian neuroendocrine liver metastasis database. J Gastrointest Surg 21: 41-48, 2017.

23. Cao LL, Lu J, Lin JX, Zheng CH, Li P, Xie JW, Wang JB Chen QY, Lin M, Tu RH and Huang CM: A novel predictive model based on preoperative blood neutrophilto-lymphocyte ratio for survival prognosis in patients with gastric neuroendocrine neoplasms. Oncotarget 7: 42045-42058, 2016

24. Villani V, Mahadevan KK, Ligorio M, Fernández-Del Castillo C, Ting DT, Sabbatino F, Zhang I, Vangel M, Ferrone S, Warshaw AL, et al: Phosphorylated histone H3 (PHH3) is a superior proliferation marker for prognosis of pancreatic neuroendocrine tumors. Ann Surg Oncol 23 (Suppl 5): S609-S617, 2016.

25. Modlin IM, Moss SF, Chung DC, Jensen RT and Snyderwine E: Priorities for improving the management of gastroenteropancreatic neuroendocrine tumors. J Natl Cancer Inst 100: 1282-1289, 2008.

26. Turner GB, Johnston BT, McCance DR, McGinty A, Watson RGP, Patterson CC and Ardill JE: Circulating markers of prognosis and response to treatment in patients with midgut carcinoid tumours. Gut 55: 1586-1591, 2006

27. Modlin IM, Oberg K, Taylor A, Drozdov I, Bodei L and Kidd M: Neuroendocrine tumor biomarkers: Current status and perspectives. Neuroendocrinology 100: 265-277, 2014.

28. Kulke MH, Siu LL, Tepper JE, Fisher G, Jaffe D, Haller DG Ellis LM, Benedetti JK, Bergsland EK, Hobday TJ, et al: Future directions in the treatment of neuroendocrine tumors: Consensus report of the National cancer institute neuroendocrine tumor clinical trials planning meeting. J Clin Oncol 29: 934-943, 2011.

29. Ambrosini V, Kunikowska J, Baudin E, Bodei L, Bouvier C, Capdevila J, Cremonesi M, de Herder WW, Dromain C, Falconi M, et al: Consensus on molecular imaging and theranostics in neuroendocrine neoplasms. Eur J Cancer 146: 56-73, 2021

30. Majala S, Seppänen H, Kemppainen J, Sundström J, Shalin-Jäntti C, Gullichsen R, Schildt J, Mustonen H, Vesterinen T, Arola J and Kauhanen S: Prediction of the aggressiveness of non-functional pancreatic neuroendocrine tumors based on the dual-tracer PET/CT. EJNMMI Res 9: 116, 2019

31. Bodei L, Sundin A, Kidd M, Prasad V and Modlin IM: The status of neuroendocrine tumor imaging: From darkness to light? Neuroendocrinology 101: 1-17, 2015

32. Righi L, Volante M, Tavaglione V, Billè A, Daniele L, Angusti T, Inzani F, Pelosi G, Rindi G and Pappotti M: Somatostatin receptor tissue distribution in lung neuroendocrine tumours: A clinicopathologic and immunohistochemical study of 218 'clinically aggressive' cases. Ann Oncol 21: 548-555, 2010
33. Reubi JC, Waser B, Cescato R, Gloor B, Stettler C and Christ E: Internalized somatostatin receptor subtype 2 in neuroendocrine tumors of octreotide-treated patients. J Clin Endocrinol Metab 95: $2343-2350,2010$

34. Lamarca A, Crona J, Ronot M, Opalinska M, Lopez Lopez C, Pezzutti D, Najran P, Carvhalo L, Franca Bezerra RO, Borg P, et al: Value of tumor growth rate (TGR) as an early biomarker predictor of patients' outcome in neuroendocrine tumors (NET)-The GREPONET Study. Oncologist 24: e1082-e1090, 2019.

35. Lamarca A, Ronot M, Moalla S, Crona J, Opalinska M, Lopez Lopez C, Pezzutti D, Najran P, Carvhalo L, Bezerra ROF, et al: Tumor growth rate as a validated early radiological biomarker able to reflect treatment-induced changes in neuroendocrine tumors: The GREPONET-2 study. Clin Cancer Res 25: 6692-6699, 2019.

36. Hanahan D and Weinberg RA: The hallmarks of cancer. Cell 100 $57-70,2000$

37. Hanahan D and Weinberg RA: Hallmarks of cancer: The next generation. Cell 144: 646-674, 2011

38. De Rubis G, Rajeev Krishnan S and Bebawy M: Liquid biopsies in cancer diagnosis, monitoring, and prognosis. Trends Pharmacol Sci 40: 172-186, 2019.

39. Malczewska A, Kos-Kudła B, Kidd M, Drozdov I, Bodei L, Matar S, Oberg K and Modlin IM: The clinical applications of a multigene liquid biopsy (NETest) in neuroendocrine tumors. Adv Med Sci 65: $18-29,2020$

40. Nehar D, Lombard-Bohas C, Olivieri S, Claustrat B, Chayvialle JA, Penes MC, Sassolas G and Borson-Chazot F: Interest of chromogranin a for diagnosis and follow-up of endocrine tumours. Clin Endocrinol (Oxf) 60: 644-652, 2004.

41. Baekdal J, Krogh J, Klose M, Holmager P, Langer SW, Oturai P, Kjaer A, Federspiel B, Hilsted L, Rehfeld JF, et al: Limited diagnostic utility of chromogranin A measurements in workup of neuroendocrine tumors. Diagnostics (Basel) 10: 881, 2020.

42. Gkolfinopoulos S, Tsapakidis K, Papadimitriou K, Papamichael D and Kountourakis P: Chromogranin A as a valid marker in oncology: Clinical application or false hopes? World J Methodol 7: 9-15, 2017.

43. Malczewska A, Kidd M, Matar S, Kos-Kudła B, Bodei L, Oberg K and Modlin IM: An assessment of circulating chromogranin a as a biomarker of bronchopulmonary neuroendocrine Neoplasia: A systematic review and meta-analysis. Neuroendocrinology 110: 198-216, 2020.

44. Zatelli MC, Torta M,Leon A, Ambrosio MR, Gion M, TomassettiP, De Braud F, Delle Fave G, Dogliotti L and degli Uberti EC; Italian CromaNet Working Group: Chromogranin A as a marker of neuroendocrine neoplasia: An Italian multicenter study. Endocr Relat Cancer 14: 473-482, 2007.

45. Campana D, Nori F, Piscitelli L, Morselli-Labate AM, Pezzilli R, Corinaldesi R and Tomassetti P: Chromogranin A: Is it a useful marker of neuroendocrine tumors? J Clin Oncol 25: 1967-1973, 2007.

46. Stridsberg M, Oberg K, Li Q, Engstrom U and Lundqvist G: Measurements of chromogranin A, chromogranin B (secretogranin I), chromogranin C (secretogranin II) and pancreastatin in plasma and urine from patients with carcinoid tumours and endocrine pancreatic tumours. J Endocrinol 144: 49-59, 1995

47. Chan DL, Clarke SJ, Diakos CI, Roach PJ, Bailey DL, Singh S and Pavlakis N: Prognostic and predictive biomarkers in neuroendocrine tumours. Crit Rev Oncol Hematol 113: 268-282, 2017

48. Baudin E, Bidart JM, Bachelot A, Ducreux M, Elias D, Rufflé P and Schlumberger M: Impact of chromogranin A measurement in the work-up of neuroendocrine tumors.Ann Oncol 12 Suppl 2: S79-S82, 2001

49. Nölting S, Kuttner A, Lauseker M, Vogeser M, Haug A, Hermann KA, Hoffmann JN, Spitzweg C, Göke B and Auernhammer CJ: Chromogranin a as serum marker for gastroenteropancreatic neuroendocrine tumors: A single center experience and literature review. Cancers (Basel) 4: 141-155, 2012.

50. Mashige F, Matsushimal Y, Kanazawal H, Sakuma I, Takai N, Besshof $\mathrm{F}$ and Ohkubo A: Acidic catecholamine metabolites and 5-hydroxyindoleacetic acid in urine: The influence of diet. Ann Clin Biochem 33: 43-49, 1996.

51. Feldman JM: Urinary serotonin in the diagnosis of carcinoid tumors. Clin Chem 32: 840-844, 1986

52. Sjöblom SM: Clinical presentation and prognosis of gastrointestinal carcinoid tumours. Scand J Gastroenterol 23: 779-787, 1988.

53. Bhattacharyya S, Raja SG, Toumpanakis C, Caplin ME, Dreyfus GD and Davar J: Outcomes, risks and complications of cardiac surgery for carcinoid heart disease. Eur J Cardiothorac Surg 40: 168-172, 2011. 
54. Niederle B, Pape UF, Costa F, Gross D, Kelestimur F, Knigge U, Öberg K, Pavel M, Perren A, Toumpanakis C, et al: ENETS consensus guidelines update for neuroendocrine neoplasms of the jejunum and ileum. Neuroendocrinology 103: 125-138, 2016.

55. Korse CM, Taal BG, de Groot CA, Bakker RH and Bonfrer JM: Chromogranin-A and $\mathrm{N}$-terminal pro-brain natriuretic peptide: An excellent pair of biomarkers for diagnostics in patients with neuroendocrine tumor. J Clin Oncol 27: 4293-4299, 2009.

56. Modlin IM, Bodei L and Kidd M: Neuroendocrine tumor biomarkers: From monoanalytes to transcripts and algorithms. Best Pract Res Clin Endocrinol Metab 30: 59-77, 2016.

57. Bhattacharyya S, Toumpanakis C, Caplin ME and Davar J: Usefulness of N-terminal pro-brain natriuretic peptide as a biomarker of the presence of carcinoid heart disease. Am J Cardiol 102: 938-942, 2008.

58. Isgrò MA, Bottoni $P$ and Scatena R: Neuron-specifi c enolase as a biomarker: Biochemical and clinical aspects. Adv Exp Med Biol 867: 125-143, 2015

59. Baudin E, Gigliotti A, Ducreux M, Ropers J, Comoy E, Sabourin JC, Bidart JM, Cailleux AF, Bonacci R, Ruffié P and Schlumberger M: Neuron-specific enolase and chromogranin $\mathrm{A}$ as markers of neuroendocrine tumours. Br J Cancer 78 : 1102-1107, 1998

60. Walter T, Chardon L, Chopin-Laly X, Raverot V, Caffin AG, Chayvialle JA, Scoazec JY and Lombard-Bohas C: Is the combination of chromogranin A and pancreatic polypeptide serum determinations of interest in the diagnosis and follow-up of gastro-entero-pancreatic neuroendocrine tumours? Eur J Cancer 48: 1766-1773, 2012.

61. Laskaratos FM, Rombouts K, Caplin M, Toumpanakis C, Thirlwell C and Mandair D: Neuroendocrine tumors and fibrosis: An unsolved mystery? Cancer 123: 4770-4790, 2017.

62. Behnes M, Brueckmann M, Lang S, Weiß C, Ahmad-Nejad P, Neumaier M, Borggrefe $M$ and Hoffmann U: Connective tissue growth factor (CTGF/CCN2): Diagnostic and prognostic value in acute heart failure. Clin Res Cardiol 103: 107-116, 2014.

63. Cunningham JL, Tsolakis AV, Jacobson A and Janson ET: Connective tissue grow th factor expression in endocrine tumors is associated with high stromal expression of alpha-smooth muscle actin. Eur J Endocrinol 163: 691-697, 2010.

64. Kidd M, Modlin I, Shapiro M, Camp R, Mane S, Usinger W and Murren J: CTGF, intestinal stellate cells and carcinoid fibrogenesis. World J Gastroenterol 13: 5208-5216, 2007.

65. Bellizzi AM: Immunohistochemistry in the diagnosis and classification of neuroendocrine neoplasms: What can brown do for you? Hum Pathol 96: 8-33, 2020.

66. McCall CM, Shi C, Cornish TC, Klimstra DS, Tang LH, Basturk O, Mun LJ, Ellison TA, Wolfgang CL, Choti MA, et al: Grading of well-differentiated pancreatic neuroendocrine tumors is improved by the inclusion of both ki67 Proliferative index and mitotic rate. Am J Surg Pathol 37: 1671-1677, 2013.

67. Bellizzi AM: Pathologic considerations in gastroenteropancreatic neuroendocrine tumors. Surg Oncol Clin N Am 29: 185-208, 2020.

68. Coriat R: Aggressive gastro-entero-pancreatic neoplasms. Ann Endocrinol (Paris) 80: 185-186, 2019.

69. Pape UF, Jann H, Müller-Nordhorn J, Bockelbrink A, Berndt U, Willich SN, Koch M, Röcken C, Rindi G and Wiedenmann B: Prognostic relevance of a novel TNM classification system for upper gastroenteropancreatic neuroendocrine tumors. Cancer 113: 256-265, 2008

70. Strosberg J, Nasir A, Coppola D, Wick M and Kvols L: Correlation between grade and prognosis in metastatic gastroenteropancreatic neuroendocrine tumors. Hum Pathol 40 1262-1268, 2009

71. Lopez-Aguiar AG, Ethun CG, Postlewait LM, Zhelnin K, Krasinskas A, El-Rayes BF, Russell MC, Sarmiento JM, Kooby DA, Staley CA, et al: Redefining the Ki-67 index stratification for low-grade pancreatic neuroendocrine tumors: Improving its prognostic value for recurrence of disease. Ann Surg Oncol 25: 290-298, 2018.

72. Zen Y and Heaton N: Elevated Ki-67 labeling index in 'synchronous liver metastases' of well differentiated enteropancreatic neuroendocrine tumor. Pathol Int 63: 532-538, 2013.

73. Grillo F, Albertelli M, Brisigotti MP, Borra T, Boschetti M, Fiocca R, Ferone D and Mastracci L: Grade increases in gastroenteropancreatic neuroendocrine tumor metastases compared to the primary tumor. Neuroendocrinology 103: 452-459, 2016
74. Shi C, Gonzalez RS, Zhao Z, Koyama T, Cornish TC, Hande KR, Walker R, Sandler M, Berlin J and Liu EH: Liver metastases of small intestine neuroendocrine tumors: Ki-67 heterogeneity and World health organization grade discordance with primary tumors. Am J Clin Pathol 143: 398-404, 2015.

75. Cives $\mathrm{M}$ and Strosberg JR: Gastroenteropancreatic neuroendocrine tumors. CA Cancer J Clin 68: 471-487, 2018.

76. Singh S, Hallet J, Rowsell C and Law CH: Variability of Ki67 labeling index in multiple neuroendocrine tumors specimens over the course of the disease. Eur J Surg Oncol 40: 1517-1522, 2014.

77. Keck KJ, Choi A, Maxwell JE, Li G, O'Dorisio TM, Breheny P, Bellizzi AM and Howe JR: Increased grade in neuroendocrine tumor metastases negatively impacts survival. Ann Surg Oncol 24: 2206-2212, 2017.

78. Sorbye H, Welin S, Langer SW, Vestermark LW, Holt N, Osterlund P, Dueland S, Hofsli E, Guren MG, Ohrling K, et al: Predictive and prognostic factors for treatment and survival in 305 patients with advanced gastrointestinal neuroendocrine carcinoma (WHO G3): The NORDIC NEC study. Ann Oncol 24 $152-160,2013$

79. Welin S, Sorbye H, Sebjornsen S, Knappskog S, Busch C and Öberg K: Clinical effect of temozolomide-based chemotherapy in poorly differentiated endocrine carcinoma after progression on first-line chemotherapy. Cancer 117: 4617-4622, 2011.

80. Jiang R, Hong X, Zhao Y and Wu W: Application of multiomics sequencing and advances in the molecular mechanisms of pancreatic neuroendocrine neoplasms. Cancer Lett 499: 39-48, 2021.

81. van Riet J, van de Werken HJG, Cuppen E, Eskens FALM, Tesselaar M, van Veenendaal LM, Klümpen HJ, Dercksen MW, Valk GD, Lolkema MP, et al: The genomic landscape of 85 advanced neuroendocrine neoplasms reveals subtype-heterogeneity and potential therapeutic targets. Nat Commun 12: 4612, 2021.

82. Scarpa A, Chang DK, Nones K, Corbo V, Patch AM, Bailey P, Lawlor RT, Johns AL, Miller DK, Mafficini A, et al: Whole-genome landscape of pancreatic neuroendocrine tumours. Nature 543: 65-71, 2017

83. Mafficini A and Scarpa A: Genomic landscape of pancreatic neuroendocrine tumours: The International cancer genome consortium. J Endocrinol 236: R161-R167, 2018.

84. Scarpa A: The landscape of molecular alterations in pancreatic and small intestinal neuroendocrine tumours. Ann Endocrinol (Paris) 80: 153-158, 2019.

85. Pea A, Yu J, Marchionni L, Noe M, Luchini C, Pulvirenti A, de Wilde RF, Brosens LA, Rezaee N, Javed A, et al: Genetic analysis of small well-differentiated pancreatic neuroendocrine tumors identifies subgroups with differing risks of liver metastases. Ann Surg 271: 566-573, 2020.

86. Cejas P, Drier Y, Dreijerink KMA, Brosens LAA, Deshpande V, Epstein CB, Conemans EB, Morsink FHM, Graham MK, Valk GD, et al: Enhancer signatures stratify and predict outcomes of non-functional pancreatic neuroendocrine tumors. Nat Med 25: 1260-1265, 2019.

87. Marinoni I: Prognostic value of DAXX/ATRX loss of expression and ALT activation in PanNETs: Is it time for clinical implementation? Gut gutjnl-2021-324664, 2021 (Epub ahead of print).

88. Lewis PW, Elsaesser SJ, Noh KM, Stadler SC and Allis CD: Daxx is an H3.3-specific histone chaperone and cooperates with ATRX in replication-independent chromatin assembly at telomeres. Proc Natl Acad Sci USA 107: 14075-14080, 2010.

89. Clynes D, Jelinska C, Xella B, Ayyub H, Scott C, Mitson M, Taylor S, Higgs DR and Gibbons RJ: Suppression of the alternative lengthening of telomere pathway by the chromatin remodelling factor ATRX. Nat Commun 6: 7538, 2015.

90. Singhi AD, Liu TC, Roncaioli JL, Cao D, Zeh HJ, Zureikat AH, Tsung A, Marsh JW, Lee KK, Hogg ME, et al: Alternative lengthening of telomeres and loss of DAXX/ATRX expression predicts metastatic disease and poor survival in patients with pancreatic neuroendocrine tumors. Clin Cancer Res 23: 600-609, 2017.

91. Pavel M, Öberg K, Falconi M Krenning EP, Sundin A, Perren A and Berruti A; ESMO Guidelines Committee: Gastroenteropancreatic neuroendocrine neoplasms: ESMO clinical practice guidelines for diagnosis, treatment and follow-up. Ann Oncol 31: 844-860, 2020.

92. VandenBussche CJ, Allison DB, Graham MK, Charu V, Lennon AM, Wolfgang CL, Hruban RH and Heaphy CM: Alternative lengthening of telomeres and ATRX/DAXX loss can be reliably detected in FNAs of pancreatic neuroendocrine tumors. Cancer Cytopathol 125: 544-551, 2017. 
93. Heaphy CM, de Wilde RF, Jiao Y, Klein AP, Edil BH, Shi C, Bettegowda C, Rodriguez FJ, Eberhart CG, Hebbar S, et al Altered telomeres in tumors with ATRX and DAXX mutations. Science 333: 425, 2011

94. Luchini C, Lawlor RT, Bersani S, Vicentini C, Paolino G, Mattiolo P, Pea A, Cingarlini S, Milella M and Scarpa A Alternative lengthening of telomeres (ALT) in pancreatic neuroendocrine tumors: Ready for prime-time in clinical practice? Curr Oncol Rep 23: 106, 2021.

95. Dogeas E, Karagkounis G, Heaphy CM, Hirose K, Pawlik TM, Wolfgang CL, Meeker A, Hruban RH, Cameron JL and Choti M: Alternative lengthening of telomeres predicts site of origin in neuroendocrine tumor liver metastases. J Am Coll Surg 218 628-635, 2014.

96. Hackeng WM, Brosens LAA, Kim JY, O'Sullivan R, Sung YN, Liu TC, Cao D, Heayn M, Brosnan-Cashman J, An S, et al: Non-functional pancreatic neuroendocrine tumours: ATRX/DAXX and alternative lengthening of telomeres (ALT) are prognostically independent from ARX/PDX1 expression and tumour size. Gut gutjnl-2020-322595, 2021 (Epub ahead of print).

97. Kim JY, Brosnan-Cashman JA, An S, Kim SJ, Song KB, Kim MS, Kim MJ, Hwang DW, Meeker AK, Yu E, et al: Alternative lengthening of telomeres in primary pancreatic neuroendocrine tumors is associated with aggressive clinical behavior and poor survival. Clin Cancer Res 23: 1598-1606, 2017.

98. Marinoni I, Kurrer AS, Vassella E, Dettmer M, Rudolph T, Banz V, Hunger F, Pasquinelli S, Speel EJ and Perren A: Loss of DAXX and ATRX are associated with chromosome instability and reduced survival of patients with pancreatic neuroendocrine tumors. Gastroenterology 146: 453-460.e5, 2014.

99. Missiaglia E, Dalai I, Barbi S, Beghelli S, Falconi M, della Peruta M, Piemonti L, Capurso G, Di Florio A, delle Fave G, et al: Pancreatic endocrine tumors: Expression profiling evidences a role for AKT-mTOR pathway. J Clin Oncol 28: 245-255, 2010 .

100. Stevenson M, Lines KE and Thakker RV: Molecular genetic studies of pancreatic neuroendocrine tumors: New therapeutic approaches. Endocrinol Metab Clin North Am 47: 525-548, 2018.

101. Zou Z, Tao T, Li H and Zhu X: mTOR signaling pathway and mTOR inhibitors in cancer: Progress and challenges. Cell Biosci 10: 31, 2020.

102. Jiao Y, Shi C, Edil BH, de Wilde RF, Klimstra DS, Maitra A, Schulick RD, Tang LH, Wolfgang CL, Choti MA, et al: DAXX/ATRX, MEN1, and mTOR pathway genes are frequently altered in pancreatic neuroendocrine tumors. Science 331: 1199-1203, 2011.

103. Coriat R, Walter T, Terris B, Couvelard A and Ruszniewski P Gastroenteropancreatic well-differentiated grade 3 neuroendocrine tumors: Review and position statement. Oncologist 21: 1191-1199, 2016.

104. Hijioka S, Hosoda W, Matsuo K, Ueno M, Furukawa M, Yoshitomi H, Kobayashi N, Ikeda M, Ito T, Nakamori S, et al: $\mathrm{Rb}$ loss and KRAS mutation are predictors of the response to platinum-based chemotherapy in pancreatic neuroendocrine neoplasm with grade 3: A Japanese multicenter pancreatic NEN-G3 study. Clin Cancer Res 23: 4625-4632, 2017.

105. Ali AS, Grönberg M, Federspiel B, Scoazec JY, Hjortland GO, Grønbæk H, Ladekarl M, Langer SW, Welin S, Vestermark LW, et al: Expression of p53 protein in high-grade gastroenteropancreatic neuroendocrine carcinoma. PLoS One 12: e0187667, 2017.

106. Basturk O, Tang L, Hruban RH, Adsay V, Yang Z, Krasinskas AM, Vakiani E, La Rosa S, Jang KT, Frankel WL, et al: Poorly differentiated neuroendocrine carcinomas of the pancreas: A clinicopathologic analysis of 44 cases. Am J Surg Pathol 38 437-447, 2014.

107. Scoazec JY: Lung and digestive neuroendocrine neoplasms From WHO classification to biomarker screening: Which perspectives? Ann Endocrinol (Paris) 80: 163-165, 2019.

108. George J, Lim JS, Jang SJ, Cun Y, Ozretić L, Kong G, Leenders F, Lu X, Fernández-Cuesta L, Bosco G, et al: Comprehensive genomic profiles of small cell lung cancer. Nature 524: 47-53, 2015.

109. Derks JL, Leblay N, Thunnissen E, van Suylen RJ, den Bakker M, Groen HJM, Smit EF, Damhuis R, van den Broek EC Chabrier A, et al: Molecular subtypes of pulmonary large-cell neuroendocrine carcinoma predict chemotherapy treatment outcome. Clin Cancer Res 24: 33-42, 2018.
110. Vijayvergia N, Boland PM, Handorf E, Gustafson KS, Gong Y, Cooper HS, Sheriff F, Astsaturov I, Cohen SJ and Engstrom PF: Molecular profiling of neuroendocrine malignancies to identify prognostic and therapeutic markers: A fox chase cancer center pilot study. Br J Cancer 115: 564-570, 2016.

111. Chen C, Notkins AL and Lan MS: Insulinoma-associated-1: From neuroendocrine tumor marker to cancer therapeutics. Mol Cancer Res 17: 1597-1604, 2019.

112. Tanigawa M, Nakayama M, Taira T, Hattori S, Mihara Y, Kondo R, Kusano H, Nakamura K, Abe Y, Ishida Y, et al: Insulinoma-associated protein 1 (INSM1) is a useful marker for pancreatic neuroendocrine tumor. Med Mol Morphol 51: 32-40, 2018.

113. Fujino K, Motooka Y, Hassan WA, Ali Abdalla MO, Sato Y, Kudoh S, Hasegawa K, Niimori-Kita K, Kobayashi H, Kubota I, et al: Insulinoma-associated protein 1 is a crucial regulator of neuroendocrine differentiation in lung cancer. Am J Pathol 185: 3164-3177, 2015.

114. Augustyn A, Borromeo M, Wang T, Fujimoto J, Shao C, Dospoy PD, Lee V, Tan C, Sullivan JP, Larsen JE, et al: ASCL1 is a lineage oncogene providing therapeutic targets for high-grade neuroendocrine lung cancers. Proc Natl Acad Sci USA 111: 14788-14793, 2014.

115. Wang H, Chen Y, Fernandez-Del Castillo C, Yilmaz O and Deshpande V: Heterogeneity in signaling pathways of gastroenteropancreatic neuroendocrine tumors: A critical look at notch signaling pathway. Mod Pathol 26: 139-147, 2013.

116. Rodriguez EF, Fite JJ, Chowsilpa S and Maleki Z Insulinoma-associated protein 1 immunostaining on cytology specimens: An institutional experience. Hum Pathol 85: 128-135, 2019.

117. Modlin IM, Drozdov I and Kidd M: The identification of gut neuroendocrine tumor disease by multiple synchronous transcript analysis in blood. PLoS One 8: 63364, 2013.

118. Kidd M, Drozdov I and Modlin I: Blood and tissue neuroendocrine tumor gene cluster analysis correlate, define hallmarks and predict disease status. Endocr Relat Cancer 22: 561-575, 2015.

119. Genzen JR, Mohlman JS, Lynch JL, Squires MW and Weiss RL: Laboratory-developed tests: A legislative and regulatory review. Clin Chem 63: 1575-1584, 2017.

120. Modlin IM, Aslanian H, Bodei L, Drozdov I and Kidd M: A PCR blood test outperforms chromogranin A in carcinoid detection and is unaffected by proton pump inhibitors. Endocr Connect 3: 215-223, 2014.

121. Liu E, Paulson S, Gulati A, Freudman J, Grosh W, Kafer S, Wickremesinghe PC, Salem RR and Bodei L: Assessment of NETest clinical utility in a U.S. registry-based study. Oncologist 24: 783-790, 2019

122. Malczewska A, Bodei L, Kidd M and Modlin IM: Blood mRNA measurement (NETest) for Neuroendocrine tumor diagnosis of image-negative liver metastatic disease. J Clin Endocrinol Metab 104: 867-872, 2019.

123. Modlin IM, Kidd M, Malczewska A, Drozdov I, Bodei L, Matar S and Chung KM: The NETest: The clinical utility of multigene blood analysis in the diagnosis and management of neuroendocrine tumors. Endocrinol Metab Clin North Am 47: 485-504, 2018

124. Öberg K, Califano A, Strosberg JR, Ma S, Pape U, Bodei L, Kaltsas G, Toumpanakis C, Goldenring JR, Frilling A and Paulson S: A meta-analysis of the accuracy of a neuroendocrine tumor mRNA genomic biomarker (NETest) in blood. Ann Oncol 31: 202-212, 2020

125. Hackeng WM, Morsink FHM, Moons LMG, Heaphy CM, Offerhaus GJA, Dreijerink KMA and Brosens LAA: Assessment of ARX expression, a novel biomarker for metastatic risk in pancreatic neuroendocrine tumors, in endoscopic ultrasound fine-needle aspiration. Diagn Cytopathol 48: 308-315, 2020.

126. Keutgen XM, Schadde E, Pommier RF, Halfdanarson TR, Howe JR and Kebebew E: Metastatic neuroendocrine tumors of the gastrointestinal tract and pancreas: A surgeon's plea to centering attention on the liver. Semin Oncol 45: 232-235, 2018.

127. Demes M, Aszyk C, Bartsch H, Schirren J and Fisseler-Eckhoff A: Differential miRNA-Expression as an adjunctive diagnostic tool in neuroendocrine tumors of the lung. Cancers (Basel) 8: 38, 2016.

128. Condrat CE, Thompson DC, Barbu MG, Bugnar OL, Boboc A, Cretoiu D, Suciu N, Cretoiu SM and Voinea SC: MiRNAs as biomarkers in disease: Latest findings regarding their role in diagnosis and prognosis. Cells 9: 276, 2020 
129. Roldo C, Missiaglia E, Hagan JP, Falconi M, Capelli P, Bersani S, Calin GA, Volinia S, Liu CG, Scarpa A and Croce CM: MicroRNA expression abnormalities in pancreatic endocrine and acinar tumors are associated with distinctive pathologic features and clinical behavior. J Clin Oncol 24: 4677-4684, 2006.

130. Vicentini C, Fassan M, D'Angelo E, Corbo V, Silvestris N, Nuovo GJ and Scarpa A: Clinical application of microRNA testing in neuroendocrine tumors of the gastrointestinal tract. Molecules 19: 2458-2468, 2014.

131. Panarelli N, Tyryshkin K, Wong JJM, Majewski A, Yang X, Scognamiglio T, Kim MK, Bogardus K, Tuschl T, Chen YT and Renwick N: Evaluating gastroenteropancreatic neuroendocrine tumors through microRNA sequencing. Endocr Relat Cancer 26: 47-57, 2019 .

132. Kulke MH, Anthony LB, Bushnell DL, de Herder WW, Goldsmith SJ, Klimstra DS, Marx SJ, Pasieka JL, Pommier RF, Yao JC, et al: NANETS treatment guidelines: Well-differentiated neuroendocrine tumors of the stomach and pancreas. Pancreas 39: 735-752, 2010.

133. Reddy KB: MicroRNA (miRNA) in cancer. Cancer Cell Int 15 : 38,2015

134. Cives M, Simone V, Rizzo FM and Silvestris F: NETs: organ-related epigenetic derangements and potential clinical applications. Oncotarget 7: 57414-57429, 2016

135. House MG, Herman JG, Guo MZ, Hooker CM, Schulick RD, Lillemoe KD, Cameron JL, Hruban RH, Maitra A and Yeo CJ Aberrant hypermethylation tumor suppressor genes in pancreatic endocrine neoplasms. Ann Surg 238: 423-431; discussion 431-2, 2003

136. Campana D, Walter T, Pusceddu S, Gelsomino F, Graillot E, Prinzi N, Spallanzani A, Fiorentino M, Barritault M, Dall'Olio F, et al: Correlation between MGMT promoter methylation and response to temozolomide-based therapy in neuroendocrine neoplasms: An observational retrospective multicenter study. Endocrine 60: 490-498, 2018.

137. Walter T, van Brakel B, Vercherat C, Hervieu V, Forestier J, Chayvialle JA, Molin Y, Lombard-Bohas C, Joly MO and Scoazec JY: O6-Methylguanine-DNA methyltransferase status in neuroendocrine tumours: Prognostic relevance and association with response to alkylating agents. $\mathrm{Br} \mathrm{J}$ Cancer 112 : 523-531, 2015.

138. Marzese DM, Hirose H and Hoon DS: Diagnostic and prognostic value of circulating tumor-related DNA in cancer patients. Expert Rev Mol Diagn 13: 827-844, 2013.

139. Jänne PA, Yang JC, Kim DW, Planchard D, Ohe Y, Ramalingam SS, Ahn MJ, Kim SW, Su WC, Horn L, et al: AZD9291 in EGFR inhibitor-resistant non-small-cell lung cancer. N Engl J Med 372: 1689-1699, 2015.

140. Schwarzenbach H, Hoon DS and Pantel K: Cell-free nucleic acids as biomarkers in cancer patients. Nat Rev Cancer 11: 426-437, 2011

141. Boons G, Vandamme T, Peeters M, Beyens M, Driessen A, Janssens K, Zwaenepoel K, Roeyen G, Van Camp G and Op de Beeck K: Cell-free DNA from metastatic pancreatic neuroendocrine tumor patients contains tumor-specific mutations and copy number variations. Front Oncol 8: 467, 2018

142. Stroun M, Anker P, Maurice P, Lyautey J, Lederrey C and Beljanski M: Neoplastic characteristics of the DNA found in the plasma of cancer patients. Oncology 46: 318-322, 1989.

143. Raptis L and Menard HA: Quantitation and characterization of plasma DNA in normals and patients with systemic lupus erythematosus. J Clin Invest 66: 1391-1399, 1980.

144. Kalluri R and Weinberg RA: The basics of epithelial-mesenchymal transition. J Clin Invest 119: 1420-1428, 2009.

145. Khan MS, Tsigani T, Rashid M, Rabouhans JS, Yu D, Luong TV, Caplin M and Meyer T: Circulating tumor cells and EpCAM expression in neuroendocrine tumors. Clin Cancer Res 17: 337-345, 2011

146. Khan MS, Kirkwood A, Tsigani T, Garcia-Hernandez J, Hartley JA, Caplin ME and Meyer T: Circulating tumor cells as prognostic markers in neuroendocrine tumors. J Clin Oncol 31: 365-372, 2013.

147. Khan MS, Kirkwood AA, Tsigani T, Lowe H, Goldstein R, Hartley JA, Caplin ME and Meyer T: Early changes in circulating tumor cells are associated with response and survival following treatment of metastatic neuroendocrine neoplasms. Clin Cancer Res 22: 79-85, 2016
148. Childs A, Vesely C, Ensell L, Lowe H, Luong TV, Caplin ME, Toumpanakis C, Thirlwell C, Hartley JA and Meyer T: Expression of somatostatin receptors 2 and 5 in circulating tumour cells from patients with neuroendocrine tumours. $\mathrm{Br}$ J Cancer 115: 1540-1547, 2016.

149. Krenning EP, Kwekkeboom DJ, Bakker WH, Breeman WA, Kooij PP, Oei HY, van Hagen M, Postema PT, de Jong M, Reubi JC, et al: Somatostatin receptor scintigraphy with [111In-DTPA-d-Phe1]- and [123I-Tyr3]-octreotide: The Rotterdam experience with more than 1000 patients. Eur J Nucl Med 20: 716-731, 1993.

150. Bombardieri E, Ambrosini V, Aktolun C, Baum RP, Bishof-Delaloye A, Del Vecchio S, Maffioli L, Mortelmans L, Oyen W, Pepe G, et al: 111In-pentetreotide scintigraphy: Procedure guidelines for tumour imaging. Eur J Nucl Med Mol Imaging 37: 1441-1448, 2010.

151. Hope TA, Bergsland EK, Bozkurt MF, Graham M, Heaney AP, Herrmann K, Howe JR, Kulke MH, Kunz PL, Mailman J, et al: Appropriate use criteria for somatostatin receptor PET imaging in neuroendocrine tumors. J Nucl Med 59: 66-74, 2018

152. Eychenne R, Bouvry C, Bourgeois M, Loyer P, Benoist E and Lepareur N: Overview of radiolabeled somatostatin analogs for cancer imaging and therapy. Molecules 25: 4012, 2020.

153. Ivanidze J, Roytman M, Sasson A, Skafida M, Fahey TJ III, Osborne JR and Dutruel SP: Molecular imaging and therapy of somatostatin receptor positive tumors. Clin Imaging 56: 146-154, 2019.

154. Graham MM, Gu X, Ginader T, Breheny P and Sunderland JJ: 68Ga-DOTATOC imaging of neuroendocrine tumors: A systematic review and metaanalysis. J Nucl Med 58: 1452-1458, 2017.

155. Sadowski SM, Neychev V, Millo C, Shih J, Nilubol N, Herscovitch P, Pacak K, Marx SJ and Kebebew E: Prospective study of $68 \mathrm{Ga}$-DOTATATE positron emission tomography/computed tomography for detecting gastro-entero-pancreatic neuroendocrine tumors and unknown primary sites. J Clin Oncol 34: 588-597, 2016.

156. Deroose CM, Hindié E, Kebebew E, Goichot B, Pacak K, Taïeb D and Imperiale A: Molecular imaging of gastroenteropancreatic neuroendocrine tumors: Current status and future directions. J Nucl Med 57: 1949-1956, 2016.

157. Miederer M, Seidl S, Buck A, Scheidhauer K, Wester HJ, Schwaiger M and Perren A: Correlation of immunohistopathological expression of somatostatin receptor 2 with standardised uptake values in 68Ga-DOTATOC PET/CT. Eur J Nucl Med Mol Imaging 36: 48-52, 2009.

158. Kratochwil C, Stefanova M, Mavriopoulou E, Holland-Letz T, Dimitrakopoulou-Strauss A, Afshar-Oromieh A, Mier W, Haberkorn U and Giesel FL: SUV of [68Ga]DOTATOC-PET/CT Predicts Response Probability of PRRT in neuroendocrine tumors. Mol Imaging Biol 17: 313-318, 2015.

159. Strosberg J, El-Haddad G, Wolin E, Hendifar A, Yao J, Chasen B, Mittra E, Kunz PL, Kulke MH, Jacene H, et al: Phase 3 trial of (177)Lu-Dotatate for Midgut Neuroendocrine tumors. N Engl J Med 376: 125-135, 2017.

160. Nicolas G, Mansi R, Vomstein S, Kaufmann J, Bouterfa H, Maecke H, Wild D and Fani M: Wider safety window with radiolabeled somatostatin receptor antagonists over agonists. J Nucl Med 56 (Suppl 3): S335, 2015

161. Fani M, Nicolas GP and Wild D: Somatostatin receptor antagonists for imaging and therapy. J Nucl Med 58 (Suppl 2): 61S-66S, 2017.

162. Nock BA, Kaloudi A, Lymperis E, Giarika A, Kulkarni HR, Klette I, Singh A, Krenning EP, de Jong M, Maina T and Baum RP: Theranostic perspectives in prostate cancer with the Gastrin-Releasing peptide receptor antagonist NeoBOMB1: Preclinical and first clinical results. J Nucl Med 58: 75-80, 2017

163. Garin E, Le Jeune F, Devillers A, Cuggia M, de Lajarte-Thirouard AS, Bouriel C, Boucher E and Raoul JL: Predictive value of 18F-FDG PET and somatostatin receptor scintigraphy in patients with metastatic endocrine tumors. J Nucl Med 50: 858-864, 2009.

164.Ezziddin S, Adler L, Sabet A, Pöppel TD, Grabellus F, Yüce A, Fischer HP, Simon B, Höller T, Biersack HJ and Nagarajah J: Prognostic stratification of metastatic gastroenteropancreatic neuroendocrine neoplasms by $18 \mathrm{~F}-\mathrm{FDG}$ PET: Feasibility of a metabolic grading system. J Nucl Med 55: 1260-1266, 2014 
165. Chan DL, Pavlakis N, Schembri GP, Bernard EJ, Hsiao E Hayes A, Barnes T, Diakos C, Khasraw M, Samra J, et al: Dual somatostatin receptor/FDG PET/CT imaging in metastatic neuroendocrine tumours: Proposal for a novel grading scheme with prognostic significance. Theranostics 7: 1149-1158, 2017.

166. Hindié E: The netpet score: Combining FDG and somatostatin receptor imaging for optimal management of patients with metastatic well-differentiated neuroendocrine tumors. Theranostics 7: 1159-1163, 2017.

167. Pavel M,O'Toole D,CostaF,Capdevila J, Gross D, Kianmanesh R, Krenning E, Knigge U, Salazar R, Pape UF, et al: ENETS consensus guidelines update for the management of distant metastatic disease of intestinal, pancreatic, bronchial neuroendocrine neoplasms (NEN) and NEN of unknown primary site. Neuroendocrinology 103: 172-185, 2016.

168. Panagiotidis E, Alshammari A, Michopoulou S, Skoura E, Naik K, Maragkoudakis E, Mohmaduvesh M, Al-Harbi M, Belda M, Caplin ME, et al: Comparison of the impact of 68Ga-DOTATATE and 18F-FDG PET/CT on clinical management in patients with neuroendocrine tumors. J Nucl Med 58: 91-96, 2017.

169. Nilica B, Waitz D, Stevanovic V, Uprimny C, Kendler D, Buxbaum S, Warwitz B, Gerardo L, Henninger B, Virgolini and Rodrigues M: Direct comparison of (68)Ga-DOTA-TOC and (18)F-FDG PET/CT in the follow-up of patients with neuroendocrine tumour treated with the first full peptide receptor radionuclide therapy cycle. Eur J Nucl Med Mol Imaging 43: $1585-1592,2016$
170.Eisenhauer EA, Therasse P, Bogaerts J, Schwartz LH, Sargent D, Ford R, Dancey J, Arbuck S, Gwyther S, Mooney M, et al: New response evaluation criteria in solid tumours: Revised RECIST guideline (version 1.1). Eur J Cancer 45: 228-247, 2009.

171. Ferté C, Fernandez M, Hollebecque A, Koscielny S, Levy A, Massard C, Balheda R, Bot B, Gomez-Roca C, Dromain C, et al: Tumor growth rate is an early indicator of antitumor drug activity in phase I clinical trials. Clin Cancer Res 20: 246-252, 2014.

172. Jain RK, Lee JJ, Ng C, Hong D, Gong J, Naing A, Wheler J and Kurzrock R: Change in tumor size by RECIST correlates linearly with overall survival in phase I oncology studies. J Clin Oncol 30: 2684-2690, 2012.

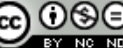

This work is licensed under a Creative Commons Attribution-NonCommercial-NoDerivatives 4.0 International (CC BY-NC-ND 4.0) License. 